\title{
Empirical testing of the CAPM on the JSE
}

\author{
Received: 5 February 2012 \\ Accepted: 20 March 2012
}

\begin{abstract}
Fama's (1970) efficient market hypothesis (EMH) and the capital asset pricing model (CAPM), jointly ascribed to Markowitz (1952), Treynor (1961), Sharpe (1964), Lintner (1965) and Mossin (1966), remain the foundation of most finance and investment courses. This is surprising, given the sustained criticism of the model and its assumptions, and is a reflection of the elegance and parsimony of the theory over the empirical evidence.

On the Johannesburg Stock Exchange (JSE), several authors have examined and noted significant inadequacies relating to the single factor CAPM, particularly with regard to the dual nature (resources versus industrial shares) which characterise this bourse. Van Rensburg and Slaney (1997) advocate the use of a two factor arbitrage pricing theory (APT) model, but show that (at least for industrial shares), additional parameters are required (Van Rensburg, 2001).

We revisit this ground using an improved methodology and data set over the period 31 December 1986 to 31 December 2011. We find that portfolios constructed on the basis of ranked beta exhibit a monotonic, inverse relationship to what the CAPM prescribes for most of the time-series. The use of the single beta CAPM is therefore inappropriate.
\end{abstract}

\begin{abstract}
"We need to be more empirical and to resist the temptation to invent laws of nature where they do not exist."
\end{abstract}

Davies and de Servigny (2011 p. vii))

\section{INTRODUCTION}

In 1990 Harry Markowitz, William Sharpe and Merton Miller were jointly awarded the Nobel prize for their contribution to the field of financial economics; notably for their work on the Capital Asset Pricing Model. Markowitz's pioneering work on asset diversification (Markowitz, 1952) introduced the concept of an efficient risk versus return frontier. Treynor (1961, 1962), Sharpe (1964), Lintner (1965a, b) and Mossin (1966), working independently, further developed Markowitz's concepts into a parsimonious theory, which is taught in all introductory finance courses, and known as the "CAPM".

The CAPM describes a simple linear model for estimating the expected return on an asset in terms of its systematic risk, beta $(\beta)$. Most students of finance are therefore familiar with the following set of equations (Wikipedia, 2012):

$\mathrm{E}\left(\mathrm{R}_{\mathrm{i}}\right)=\mathrm{R}_{\mathrm{f}}+\beta_{\mathrm{i}}\left(\mathrm{E}\left(\mathrm{R}_{\mathrm{m}}\right)-\mathrm{R}_{\mathrm{f}}\right)$

where:

$E\left(R_{i}\right)$ is the expected return on the share (asset)

*GIBS, University of Pretoria, Republic of South Africa.

Email: mchlwrd@gmail.com
$R_{f}$ is the risk-free rate of interest, such as interest arising from government bonds

$\beta_{\mathrm{i}}$ (the beta) is the sensitivity of the expected excess asset returns to the expected excess market returns, or also

$\beta_{\mathrm{i}}=\frac{\operatorname{Cov}\left(\mathrm{R}_{\mathrm{i}}, \mathrm{R}_{\mathrm{m}}\right)}{\operatorname{Var}\left(\mathrm{R}_{\mathrm{m}}\right)}$

$E\left(R_{m}\right)$ is the expected return of the market

$\left(\mathrm{E}\left(\mathrm{R}_{\mathrm{m}}\right)-\mathrm{R}_{\mathrm{f}}\right)$ is sometimes known as the market premium (the difference between the expected market rate of return and the risk-free rate of return).

The elegance of the theory and the simple linear, positive relationship to define risk and return are intuitively appealing. Furthermore, the metric of expected return, which is the subject of the CAPM formula, has significant importance in the fields of financial investment and corporate finance, as it forms the basis of valuation theory.

For example, Gordon's (1959) dividend discount model assumes the value of a share can be estimated by discounting all future dividends to a present value, using the share's expected return as the discount rate. Alternative valuation methods discount a share's future free cash flows using the weighted cost of debt and equity capital, the latter being the shares expected return. Although other methods for estimating a share's expected return exist, the CAPM is the dominant approach. As such, the CAPM is a core construct of modern finance.

However, despite its theoretical and practical appeal, the empirical evidence in support of the CAPM is at 
best weak, with many studies showing that there is no relationship between systematic risk and return, and some studies showing an inverse relationship!

\section{LITERATURE REVIEW}

Despite a large body of empirical research in the 1970s and 1980s, beta and the CAPM were not seriously questioned until the widely acclaimed paper of Fama and French (1992). Fama and French isolated the role of beta and its association with returns, by controlling for other company related variables: size, book to market, earnings yield and leverage. They summarise their findings as follows: "Our bottom-line results are: (a) beta does not seem to explain the cross-section of average stock returns, and (b) the combination of size and book to market equity seems to absorb the roles of leverage and earnings yield in average stock returns, at least during our 1963-1990 sample period. If assets are priced rationally, our results suggest that stock risks are multi-dimensional" (p 428).

Unsurprisingly, the Fama and French (1992) paper drew considerable criticism; but there was general agreement on two related issues. Firstly, the relationship between return and beta is weak over the period 1941 to 1990 in US data, and almost nonexistent in the last 30 years of this sample. Secondly, there is general agreement that returns are negatively related to both price-earnings and to the market to book ratio. In addition to these variables, Cathcart (1997) found that momentum in share returns increased the returns of shares with otherwise identical betas, and Ang, Hodrick, Xing and Zhang (2009) found that amongst firms with the same beta, those that exhibited a greater sensitivity to volatility in market returns, had significantly lower returns. Since the CAPM states that the expected returns on stocks should be related only to beta, and not to other factors, these are obviously damaging findings (Hillier, Ross, Westerfield, Jaffe and Jordan, 2010).

Fama and French (2004) updated their earlier work using data from 1923 to 2003. Each December they estimated a beta for every share on the NYSE, AMEX and NASDAQ using 2-5 years of prior monthly return data. They constructed ten portfolios based on ranked beta, and measured the portfolio returns over the next 12 months. In their paper they construct a graph showing the average return for each decile against its average beta, and show that the returns on low beta shares are massively under-estimated by the CAPM, and vice-versa for high beta shares. They conclude, that over the long run (and using US data), there has been essentially no relationship between beta and return.

Perhaps the strongest antagonist of the CAPM and beta is James Montier, who devotes an entire chapter in his book on behavioural finance to the subject (Montier, 1997). He quotes the work of Jeremy Grantham, who reveals that amongst the largest 600 stocks in the US since 1963, those with the lowest beta have the highest return, and those with the highest beta have the lowest return - the complete inverse of the CAPM predictions. He argues from Clarke, de Silva and Thorley (2006) that the CAPM is clearly violated if a minimum variance portfolio consistently (since 1968) generates higher returns with lower risk than the market index. In addition he presents evidence that other priced variables, including so-called fundamentals, have a stronger association than beta with share returns. Montier concludes that the CAPM is useless to practitioners, and fails because the assumptions under-pinning the theory are "ludicrous".

On the JSE, van Rensburg and Robertson (2003) provide the most credible analysis of the empirical evidence for the CAPM on the JSE to date. They use the BARRA share monthly total return data over the period 1990 to 2000, controlling for survivor bias and corporate events. Following the Fama and French (1992) methodology, they find a size effect and a price to earnings effect, but conclude that "if anything, beta is inversely related to returns!" (van Rensburg and Robertson, 2003:15). Their study suffers however from two issues. Firstly, they use only 10 years of data, which they themselves indicate is too short. Secondly, although they apply a thin-trading filter, their results show evidence of the inclusion of many small capitalisation shares, sometimes having up to 220 fledgling shares beyond the 160 shares in the All Share Index. The inclusion of these shares into equal weighted portfolios results in a very strong bias towards fledgling stocks which we feel is inappropriate.

Strugnell, Gilbert and Kruger (2011:1) "build on the observations of van Rensburg and Robertson (2003)". They use monthly share price data from INET over the period $1994-2007$. To control for thin trading they use both the Scholes and Williams (1977) as well as the Dimson (1979) methods for estimating beta from nonsynchronous returns. They find support for a size and price-earnings effect as well as an inverse relationship between return and beta. Their study suffers from the same problems as van Rensburg and Robertson (2003); too short a time horizon and the inclusion of very small capitalisation shares. In addition, whilst they try to correct for corporate events, they note "numerous anomalies and apparent inaccuracies" in the data requiring "minor adjustments" for delisted shares (Gilbert and Kruger, 2011:4). Furthermore, lacking actual dividend data, their method of adding $1 / 12^{\text {th }}$ of the dividend yield to re-construct monthly total returns is less than ideal.

As indicated above, the CAPM is a central tenet to financial theory and practice. With this in mind, our objective is to re-examine the South African data in a 
more comprehensive manner for evidence of an association between beta and returns. Firstly, we use a significantly longer time-series of data (1985 to 2011). Secondly, we take considerable trouble to ensure that the data is appropriate, complete and accurate. Thirdly, we offer a simpler and better methodology.

\section{METHODOLOGY}

We use 26 years of JSE daily share price data from 1985 to 2011 in combination with company financial statement data from I-NET. Our data includes all companies which were listed on the main board of the JSE over this time period, including new listings and delisted companies. Changes in share prices which were a result of share splits or consolidations have been backwards adjusted in the time series data.

Where a company in the sample unbundles (spins-off) a subsidiary, we include the returns from the newly listed subsidiary with those of the original holding company for the remainder of the quarterly review period. Thereafter we treat both companies individually.

Dividend receipts constitute a significant portion of the return an investor receives, and we therefore include dividends in share returns using the I-NET historical time series of cash dividend pay-outs. On the same basis we also include scrip dividends in share returns. We do not however account for share buybacks on the grounds that these are a form of capital reduction which only affects those shareholders who exit the company. We ignore shares granted as compensation to managers.

When shares de-list within the quarter we thereafter use a zero return. We include the impact of unbundlings as described above, and exclude data errors on (only) the day these occur by treating as zero any daily return on shares which are less than $-40 \%$ or greater than $+40 \%{ }^{1}$. We include newly listed shares at the start of the next quarter and drop delisted shares at the end of the quarter on the basis of their last price when they ceased trading. We track name changes and follow these through in the sample.

Although there are typically more than 350 companies listed on the JSE over the time frame, the All Share Index (ALSI) comprises only the largest 160 companies, but represents around $99 \%$ of the total market capitalisation - see Figure 1. Those companies falling outside of the ALSI are considered too small and too illiquid for most investors. We conduct our initial analysis on all the listed companies, but construct portfolios using only the top 160 ranked by market capitalisation, after ensuring that there are no missing variables in any of the sample companies.

We divide our methodology into two parts.

\section{Part A}

There is a significant literature on how to estimate beta, particularly in a thinly traded environment. Consequently, we estimate beta coefficients for each company in a variety of ways. Firstly, we calculate beta in terms of Equation 2 as the slope coefficient of the OLS linear regression equation using monthly total return data over the prior 60 months against the synchronous ALSI total returns (J203T) on the $X$ axis. In those instances where we have less than 60 prior data points we estimate the beta using the data we have, but with at least 24 data points.

We also estimate betas using 2 years of prior weekly total return data, using the same approach described above.

Thirdly, we use the Dimson (1979) aggregated coefficients methodology which includes nonsynchronous returns as a means to improve beta estimation for thinly traded shares. Although we do not believe that thin trading is a particular problem in the top 160 shares in our sample, the aggregated coefficient approach does provide a robust methodology for the estimation of beta. Dimson advocates the aggregation of the OLS betas of one leading and several lagged OLS estimates in a multiple regression as shown in Equation 3.

$r_{i, t}=\widehat{\alpha}_{i}+\sum_{k=-n}^{1} \hat{\beta}_{i, k} \cdot r_{m, t+k}+\epsilon_{i, t}$

where

$r_{i, t} \quad$ is the share return in time $t$

$r_{m, t+k}$ is the market return at time $t$

$\hat{\beta}_{i, k} \quad$ is the beta estimate for share $i$ at lag $k$ in the multiple regression

$\mathrm{k}$ is the period of lag (we use 4 lags, synchronous, and one lead)

Using the 160 companies in the sample we construct five equal weighted portfolios at the start of each quarter, from 31 December 1989, after ranking the sample in terms of descending beta. On a daily basis we calculate the return for each of the 32 shares (including any dividends) in each portfolio, and calculate the value of each of the five portfolios from a base of one.

\footnotetext{
${ }^{1}$ We also print out a list of all these exclusions, which typically relate to unbundlings (spin-offs) or data errors.
} 


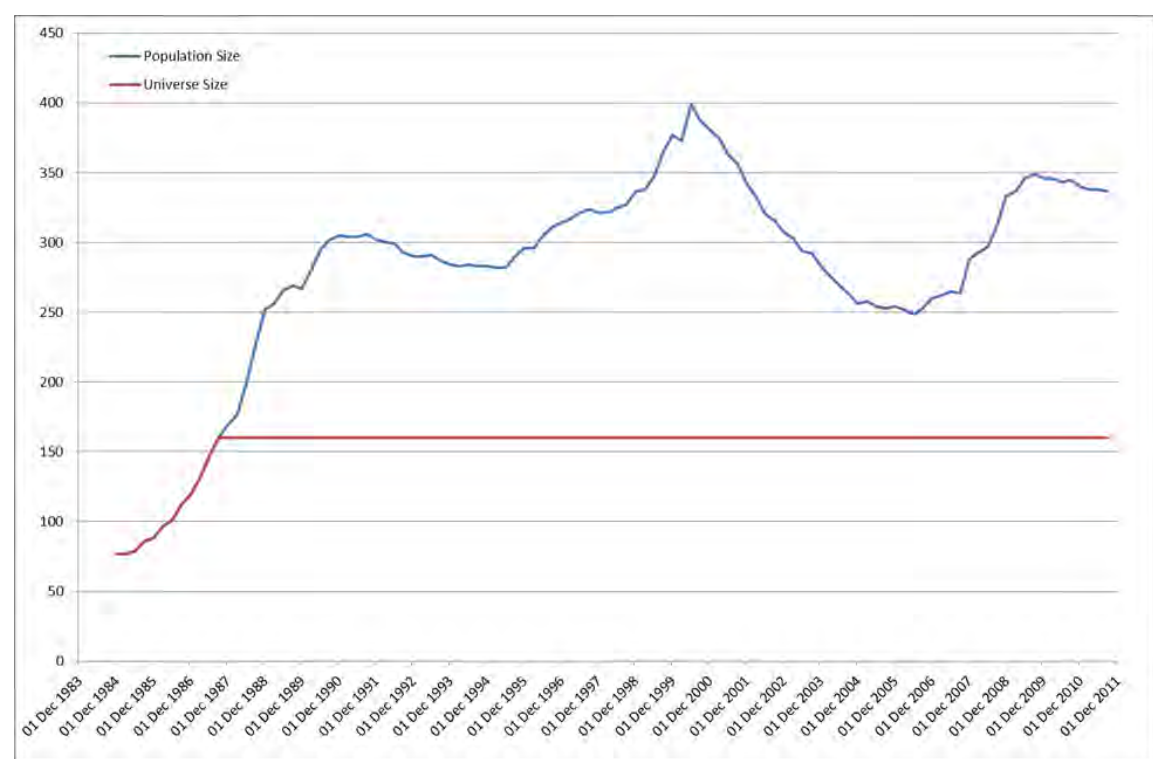

Figure 1: The population of JSE listed shares and the universe we use in our sample

On the last day of each quarter we retain the value of each portfolio. We repeat the above process with a revised list of the top 160 companies. We recalculate betas (using out-of-sample data) and reconstitute the five portfolios as described above. We continue this approach each quarter until the last quarter of 2011.

We ignore transaction costs that relate to the churn in each portfolio on the grounds that these will be approximately the same between portfolios and thus immaterial in a relative sense.

The traditional approach of most researchers who have conducted equivalent studies has been to report average portfolio returns and to use t-tests to test for significant differences in the results. We concur that the construction of portfolios of shares is a necessary approach to reduce the volatility of the data. However, we view the use of average monthly or quarterly returns as methodologically weak compared to cumulative returns, in much the same way as average abnormal returns reveal relatively little compared to cumulative abnormal returns in event studies. Our approach therefore is to plot the cumulative index (value) of each portfolio over the timeframe and to visually compare the results.

To aid the interpretation of the resulting graph of portfolio cumulative values, we construct a "price relative" by dividing the value of the highest beta portfolio by that of the lowest beta portfolio on each day, and plot this on the second (right hand side) $Y$ axis. In effect, the price relative compares the difference between the two portfolios and is akin to the excess return an investor who holds the shares in the large beta portfolio would make over those of the low beta portfolio. Importantly, the slope of the price relative also reveals over which time periods the highest beta portfolio out-performed the low beta portfolio. In the periods when the slope of the price relative is upwards the high beta portfolio is outperforming, and vice-versa. If the slope of the price relative is flat for any period of time, then no out performance is occurring, and there is no difference between the portfolios.

We also construct methodologies to test the robustness of our data and our methodology. Firstly, to test the integrity of our share return data we construct a market capitalisation weighted index (including dividends) commencing 30 June 1995 and compare this to the J203T, the JSE total return index on the top 160 shares. Because the J203T was only launched in 2003, we use the JSE's backwards-constructed J203 for the 8 years prior to this. We expect our reconstructed index to closely track the J203T.

Secondly, we test our methodology as follows. We follow the identical data selection and portfolio construction described above, except that we "randomise" the ranking of the 160 shares in the sample by ranking on a random number and not beta. We expect no clear separation between the portfolios on this basis, and anticipate that the results will provide an indication of the level of randomness in the methodology.

\section{Part B}

Van Rensburg and Robertson (2003), Strugnell, Gilbert and Kruger (2011), Fama and French (2004) and others have shown that a number of other share characteristics are correlated to beta. In particular, size (market capitalisation), price to earnings (value versus growth) and resources versus non-resource shares have been shown to be associated with share returns. We examine these inter-relationships by calculating each of the five portfolio's characteristics (portfolio return; and for the shares in each portfolio, the median 
beta; median market capitalisation; median earningsyield and percentage of resources versus nonresource shares) each quarter. We plot the time-series for each characteristic and construct a correlation matrix of the data.

\section{RESULTS}

Figure 2 shows a re-construction of the J203T total return ALSI index over the period June 1995 December 2011 using our share price and dividend data and compares this with the J203T itself.

As can be observed there is a strong fit between the actual index and our replicated index. The green coloured price relative does indicate a slight discrepancy, with the replicated index showing higher returns over the period 1998 to 2003, but these are dissipated over the remaining period of the data. We conclude that our data is accurate.

Figure 3 shows the results of randomly ranking the top 160 shares each quarter into five portfolios.

Over the 25 year period of our study there is an observable difference in the final performance of the five portfolios. However, instead of a clear and sequential separation between the lines, we find (as expected) a pattern of randomness. This is a good indication that there is no inherent bias in our methodology. Portfolio 5 (smallest random numbers) appears to track the J203T index for the last 10 years of the data, whereas the other 4 portfolios end at a slightly higher level but in a random sequence $(4,2,3$, 1 ). It should be noted, that on average, our five equalweighted portfolios slightly out-perform the market capitalisation weighted J203T, indicating a small-size effect. The fact that the slope of the green price relatives appears to be flat since about December 2000 , indicates that any size effect in the data is no longer material.

\section{Part A}

In part $A$ of our results we show the performance of portfolios of shares, ranked each quarter on the basis of prior beta (descending), (Figures 4 to 7 below).

We observe very similar results in the performance of the portfolios using different methods of beta estimation in Figures 4, 5, 6 and 7. This is indicative of the fact that whilst there may be nuances in the manner in which beta is calculated, this is not a pertinent issue in this sample of shares. Arguably, the conventional approach of using 60 monthly returns and an OLS estimation methodology provides the best results, giving the biggest spread between highest and lowest portfolios and the correct ordering between portfolios consistently through the time-series (Figure 4).

In each graph the large beta portfolio significantly under-performs the smaller beta portfolios. Using Figure 4 as an example, the portfolio with the highest beta shares (BetaOLS60m1) exhibits an annualised total return of $7,1 \%$ pa over the 25 year period. The portfolio with the lowest ranked betas (BetaOLS60m5) exhibits an annualised return of $21,6 \%$ pa, significantly exceeding the $15,8 \%$ pa return of the J203T index. The downward sloping price relatives in each graph also show that the under-performance of the large beta portfolios occurred in the first 20 years of the timeseries. Thereafter, for the about last 7 years, the price relatives are essentially flat. We find therefore a negative relationship between beta and returns between 1986 and 2004, and that there has been no relationship between beta and returns for the last 7 years.

The beta coefficient is a measure of market related or systematic risk. To examine the issue further, we repeat the experiment by ranking shares in terms of total risk as measured by volatility. To calculate volatility we use the 60 trading days of return data prior to the start of each quarterly review period.

We observe a very similar pattern of results, although there is less spread between the closing returns in highest versus lowest portfolios. Portfolio 1 (VOL1), containing those shares with the highest levels of volatility, produces the lowest returns. We conclude that risk as measured by high levels of volatility, is to be avoided. The results are summarised in Table 1.

\section{Part B}

In part B of our results we show the characteristics of the shares in each of the portfolios. In this section we only show the results for the portfolios ranked by betas estimated using OLS regression on 60 monthly returns. Figure 9 contains the portfolio median betas. In Figures 10 to 12 we show the portfolio rank percentiles for selected characteristics. For interpretation purposes, it is important to note that the ranking is done ascending, so large percentiles indicate high levels in the characteristic. In Figure 13 we show the number of resource shares in each portfolio. 


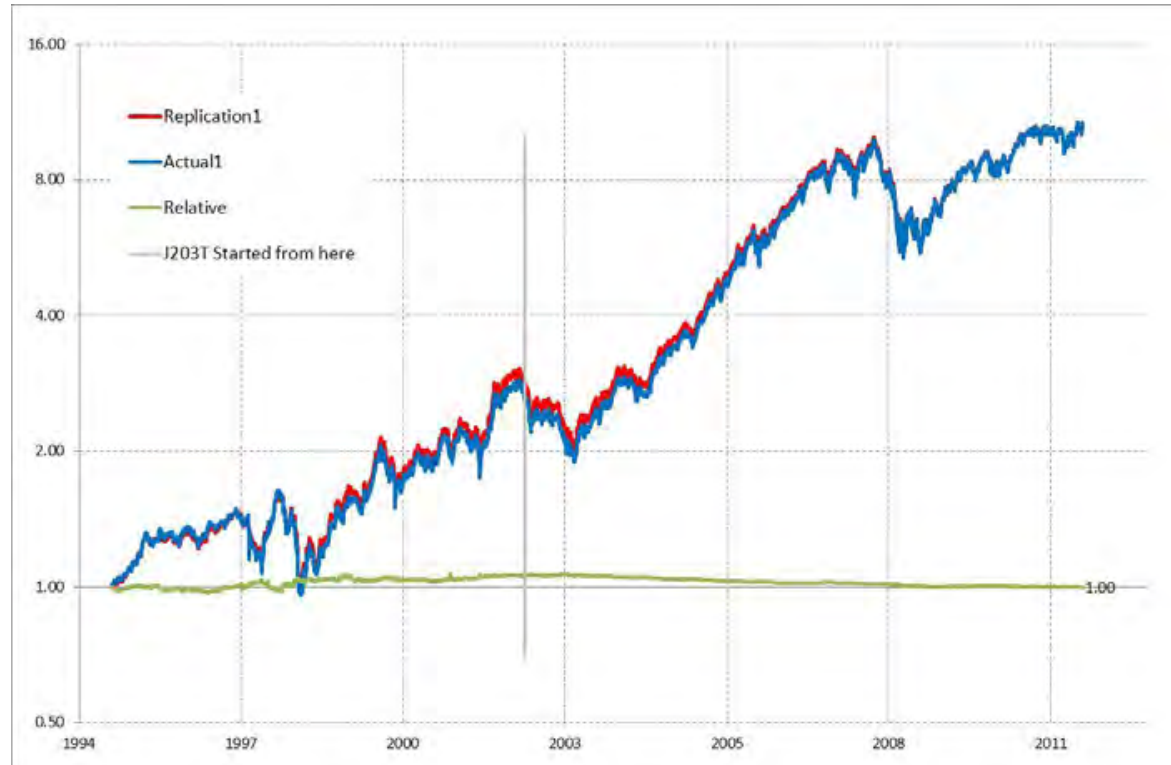

Figure 2: Replicating the J203T index using our share price and dividend data

Table 1: Annualised returns for equal weighted portfolios over the period 31 Dec $1986-31$ Dec 2011

\begin{tabular}{|c|c|c|c|c|c|c|c|}
\hline Risk Measure & $\begin{array}{c}\text { Number of } \\
\text { Observations }\end{array}$ & $\begin{array}{l}\text { ALSI } \\
\text { Index } \\
\text { R203 }\end{array}$ & $\begin{array}{l}\text { Highest } \\
\text { Beta } \\
\text { Quintile }\end{array}$ & Quintile 2 & Quintile 3 & Quintile 4 & $\begin{array}{l}\text { Lowest } \\
\text { Beta } \\
\text { Quintile }\end{array}$ \\
\hline OLS Monthly Beta & 60 & $15,7 \%$ & $7,7 \%$ & $12,1 \%$ & $18,1 \%$ & $21,6 \%$ & $20,4 \%$ \\
\hline OLS Weekly Beta & 104 & $15,7 \%$ & $4,6 \%$ & $15,4 \%$ & $20,4 \%$ & $19,9 \%$ & $19,3 \%$ \\
\hline Dimson Monthly Beta & 60 & $15,7 \%$ & $7,9 \%$ & $16,3 \%$ & $19,3 \%$ & $19,0 \%$ & $17,4 \%$ \\
\hline Dimson Weekly Beta & 104 & $15,7 \%$ & $5,7 \%$ & $15,3 \%$ & $19,0 \%$ & $19,5 \%$ & $20,8 \%$ \\
\hline Volatility & & $15,7 \%$ & $9,7 \%$ & $13,5 \%$ & $17,7 \%$ & $20,8 \%$ & $18,2 \%$ \\
\hline Average annualised Return & & $15,7 \%$ & $7,1 \%$ & $14,5 \%$ & $18,9 \%$ & $20,2 \%$ & $19,2 \%$ \\
\hline
\end{tabular}

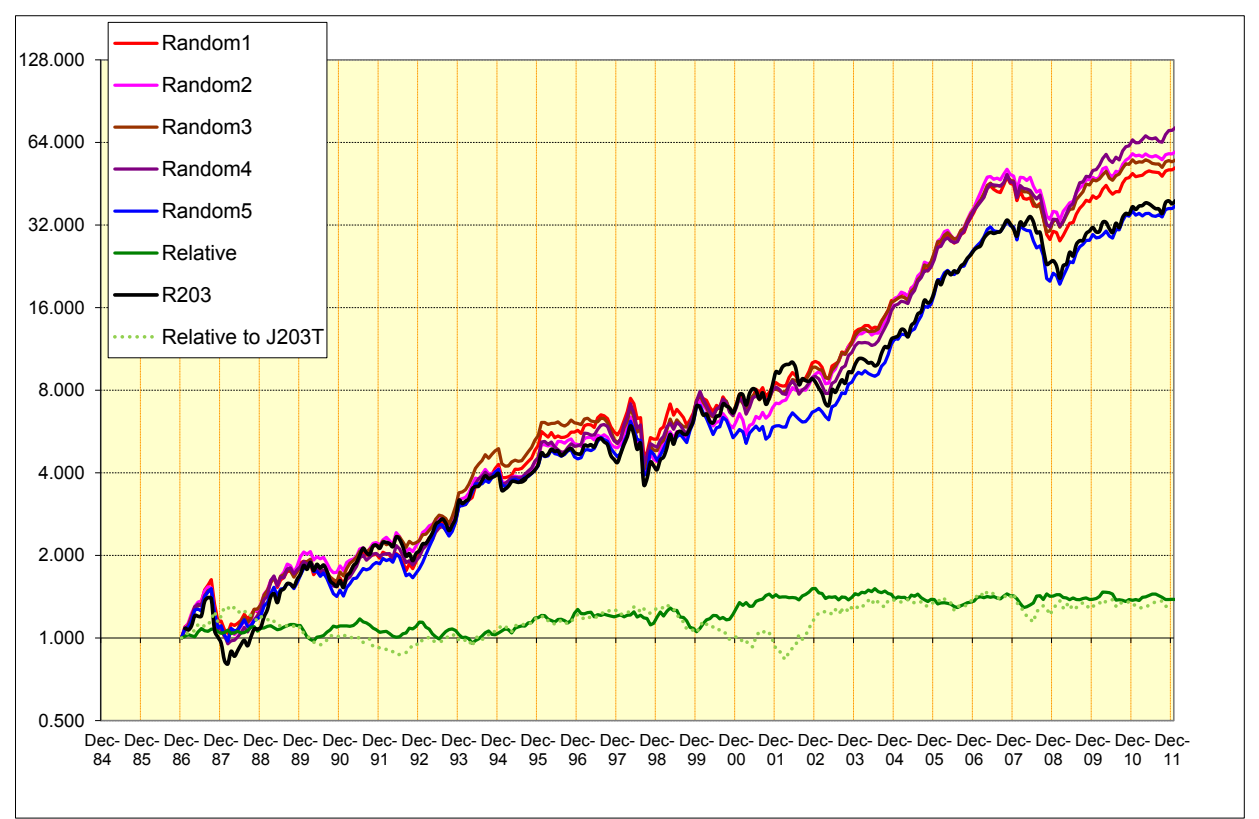

Figure 3: Random allocation of shares into portfolios 
As expected given the prior ranking on beta, the portfolio median betas are systematically spread across the time-series. There is evidence of cyclicality in the data, and an upward trend in the higher betas.

There is no clear pattern in terms of earnings yield in the portfolios across the time-series.

In Figure 11 there is evidence of a persistent size effect. Portfolio 5 (Beta Very Low) is typically ranked around the $30^{\text {th }}$ percentile, indicating low market capitalisation. Although there is some evidence of an ordering in the data (lower beta portfolios have lower market capitalisation), Portfolio 1 (Beta Very High) often spoils the pattern.

There is no clear pattern in terms of price to book in the portfolios across the time-series.
Figure 13 shows the number of resource shares in each portfolio across the time series. Portfolio 1 (Beta Very High) is notable. With the exception of the 5 year period between June 1998 and December 2003, Portfolio 1 has a significantly higher weighting of resource shares than the other portfolios. The exception period coincides with the market crash in 1988. The large moves in the J203 index are likely to have caused higher betas in industrial shares for the next 60 months.

We conclude this section by calculating the correlations between the portfolio median betas and the ranked percentiles of the characteristics across the time-series. Table 2 shows the results.

Table 2: Correlation matrices for the total sample ( $5 \%$ significance in bold)

\begin{tabular}{|c|c|c|c|c|c|}
\hline Total Sample $(n=5 * 108)$ & Median Beta & $\begin{array}{c}\text { Price to } \\
\text { Book Rank } \\
\text { Percentile }\end{array}$ & $\begin{array}{l}\text { Earnings } \\
\text { Yield Rank } \\
\text { Percentile } \\
\end{array}$ & $\begin{array}{c}\text { Market Cap } \\
\text { Rank } \\
\text { Percentile }\end{array}$ & $\begin{array}{c}\text { Percentage } \\
\text { Resource }\end{array}$ \\
\hline Median Beta & 1,00 & 0,01 & $-0,27$ & 0,68 & 0,65 \\
\hline Price to Book Rank Percentile & 0,01 & 1,00 & 0,03 & 0,07 & $-0,23$ \\
\hline Earnings Yield Rank Percentile & $-0,27$ & 0,03 & 1,00 & $-0,22$ & $-0,29$ \\
\hline Market Cap Rank Percentile & 0,68 & 0,07 & $-0,22$ & 1,00 & 0,40 \\
\hline Percentage Resource & 0,65 & $-0,23$ & $-0,29$ & 0,40 & 1,00 \\
\hline
\end{tabular}

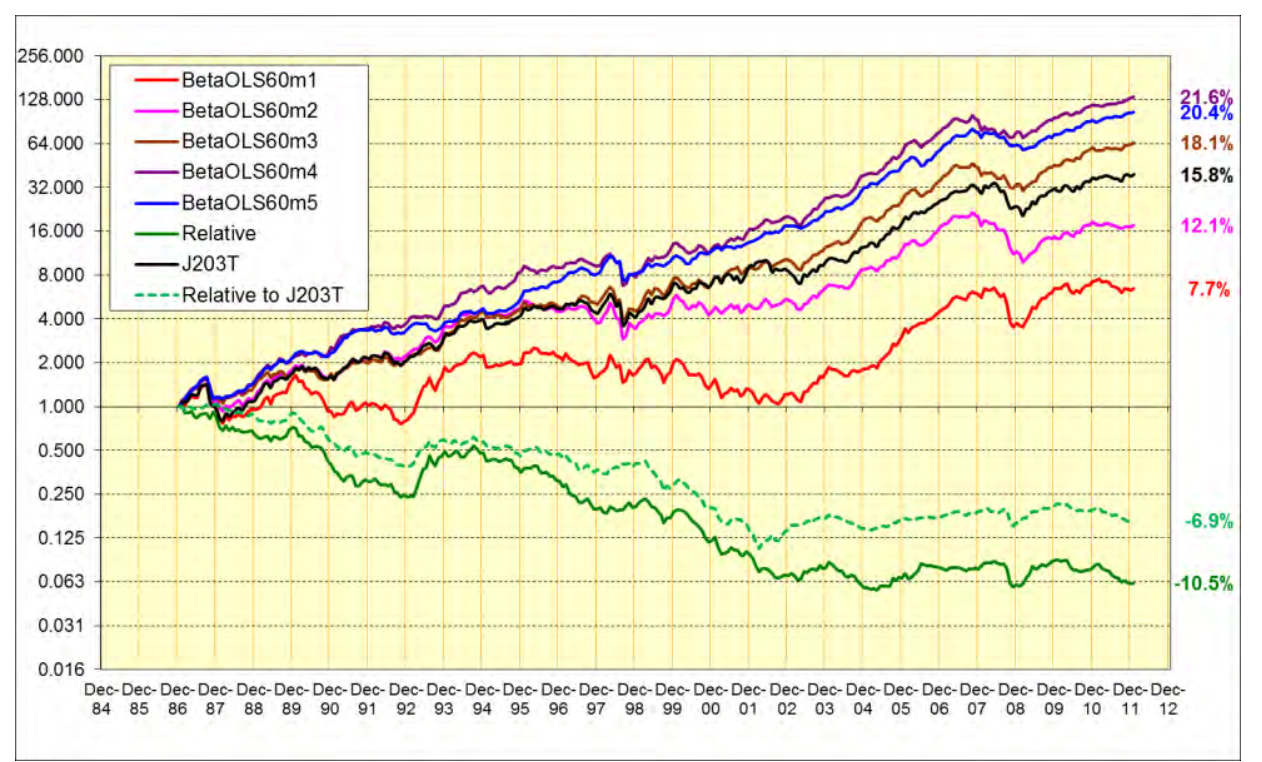

Figure 4: Portfolios ranked in terms of OLS betas using 60 months of prior data 


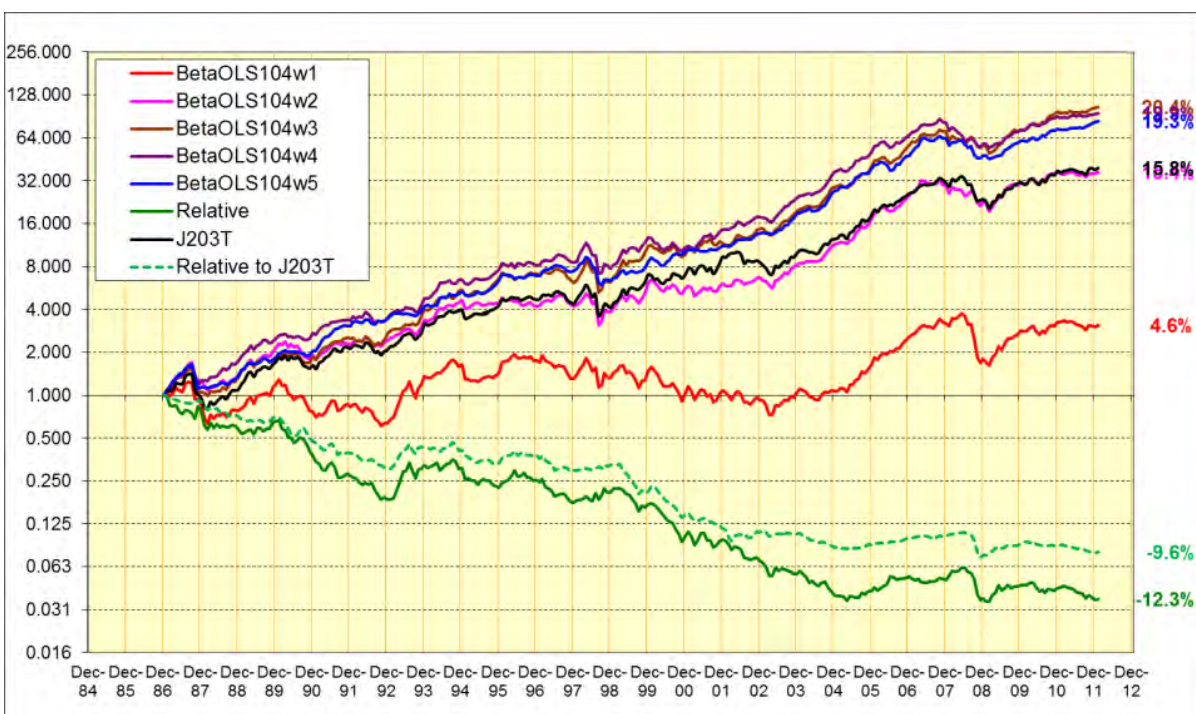

Figure 5: Portfolios ranked in terms of OLS betas using 104 weeks of prior data

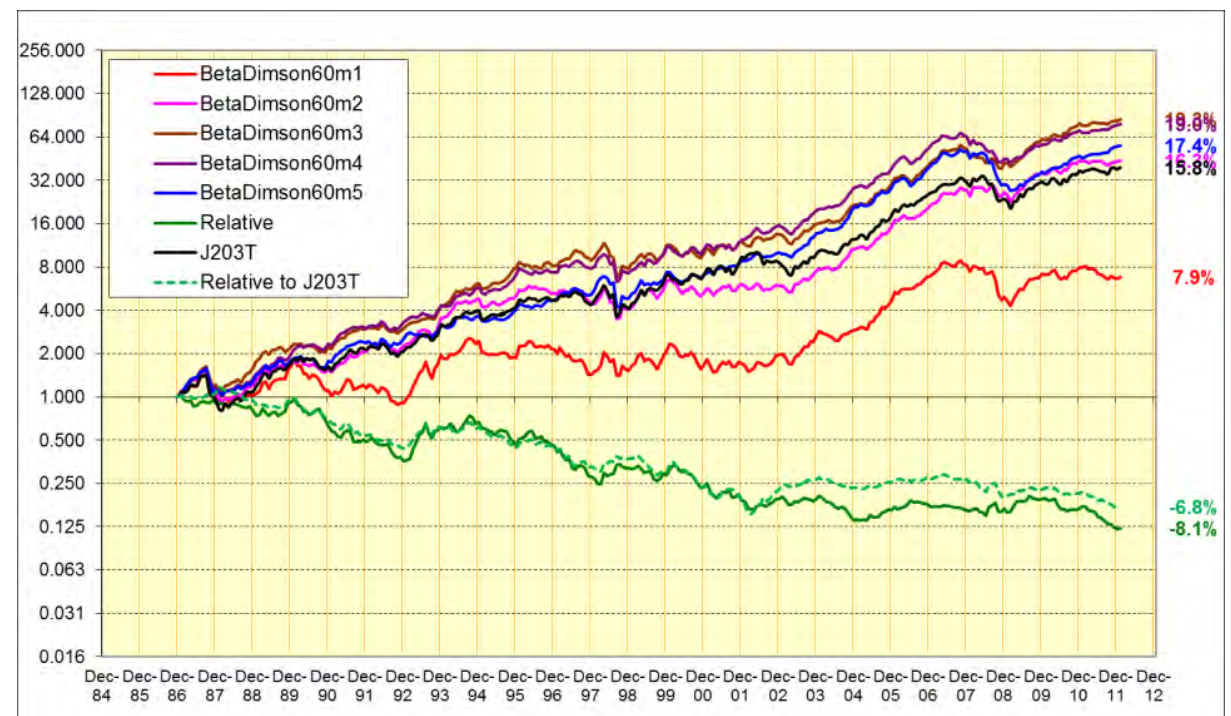

Figure 6: Portfolios ranked in terms of Dimson betas using 60 months of prior data

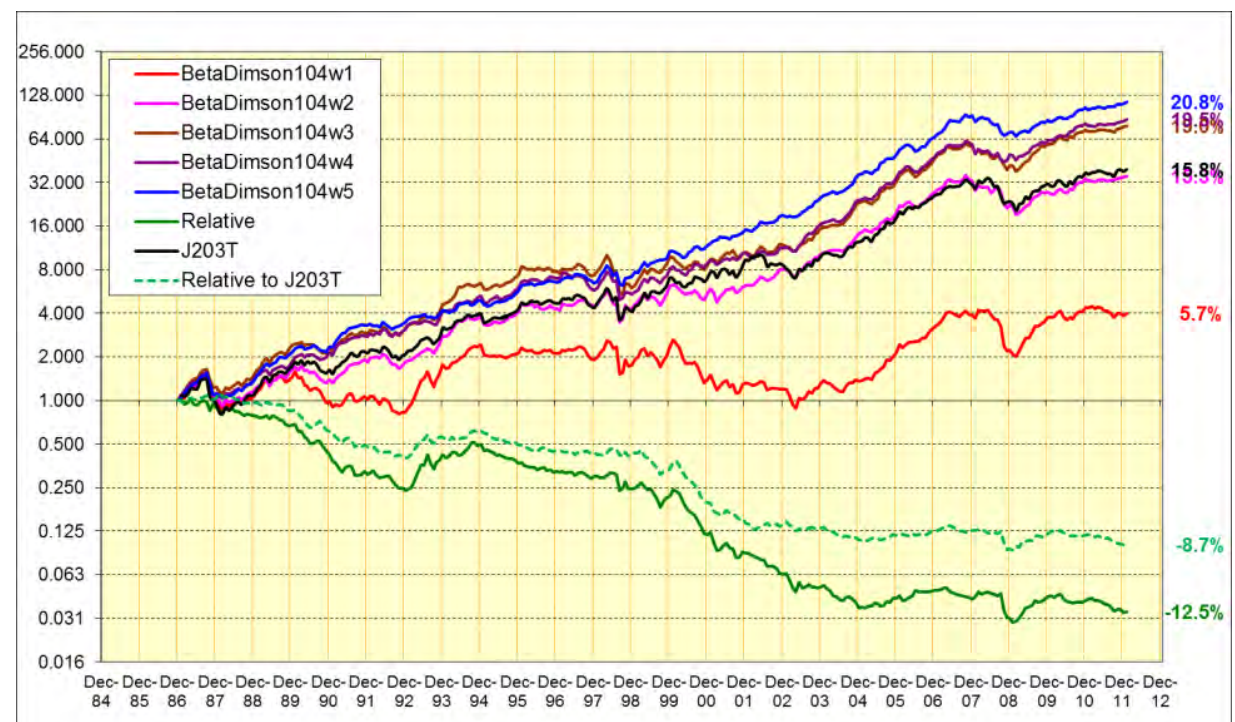

Figure 7: Portfolios ranked in terms of Dimson betas using 104 weeks of prior data 


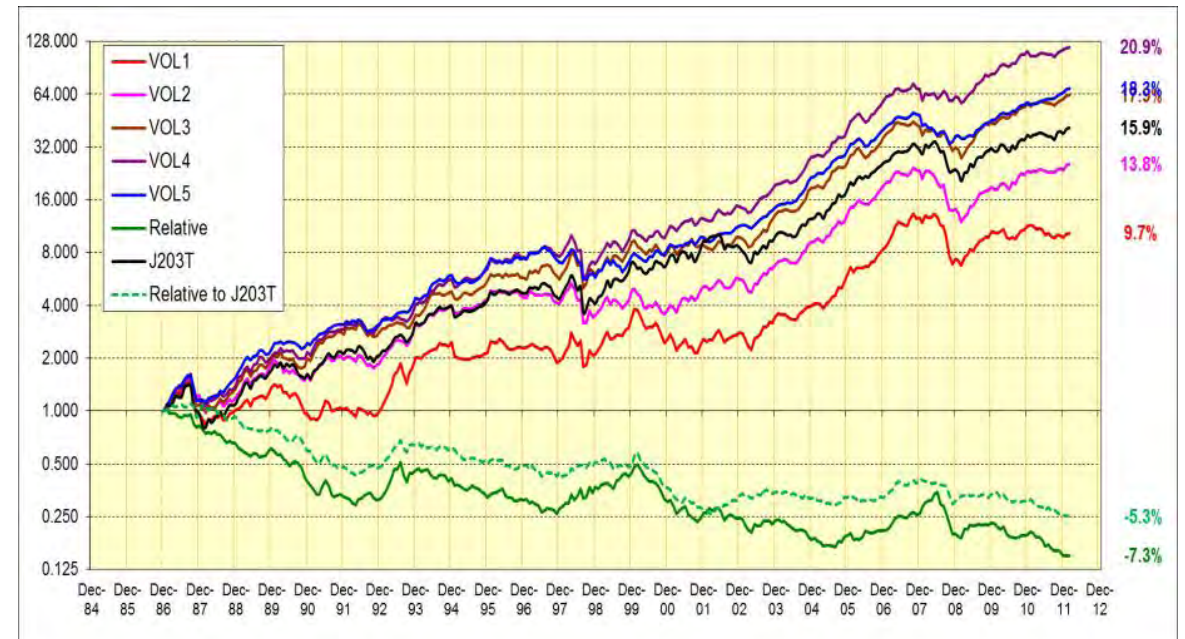

Figure 8: Portfolios ranked in terms of volatility, measured using 60 prior daily returns

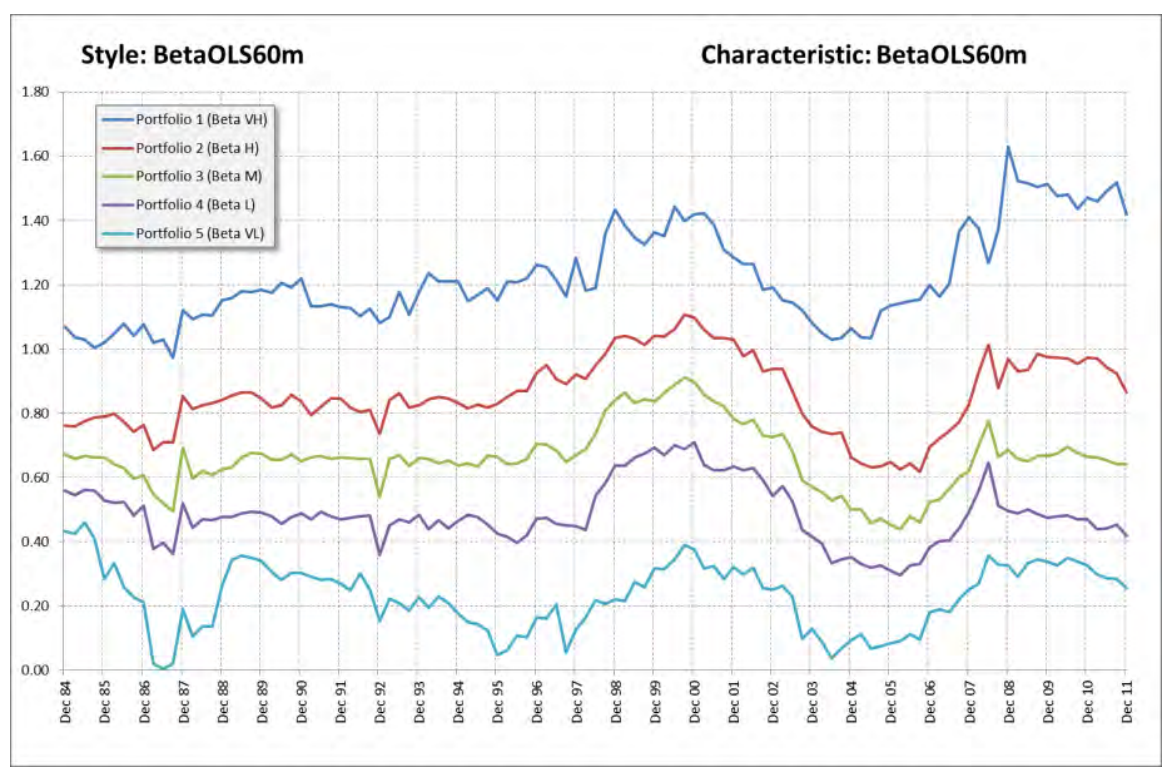

Figure 9: Portfolio median betas

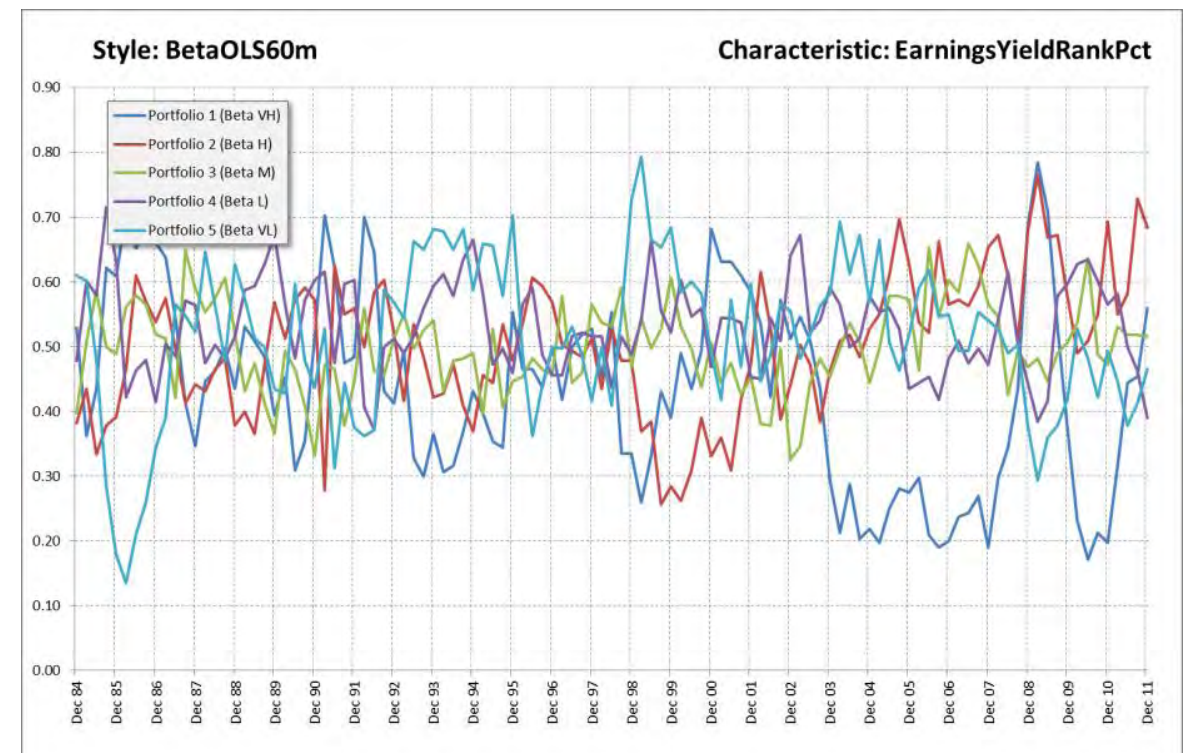

Figure 10: Portfolio characteristic: Earnings yield rank percentage 


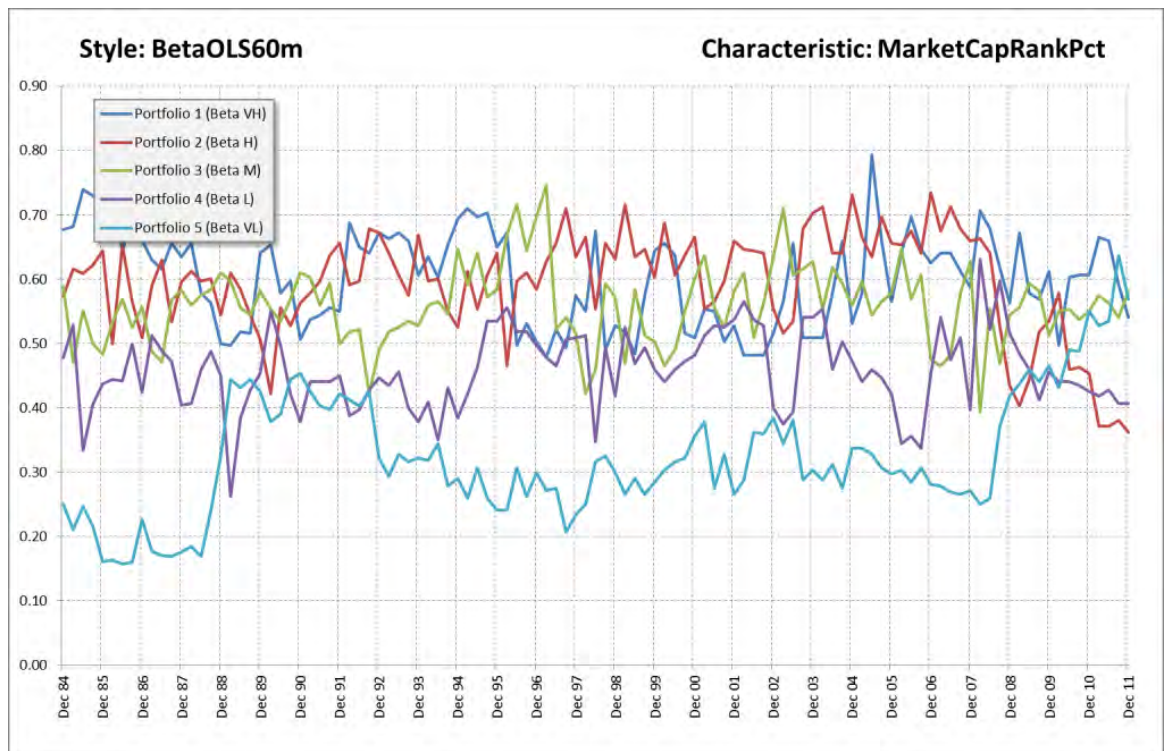

Figure 11: Portfolio characteristic: Market capitalisation rank percentage

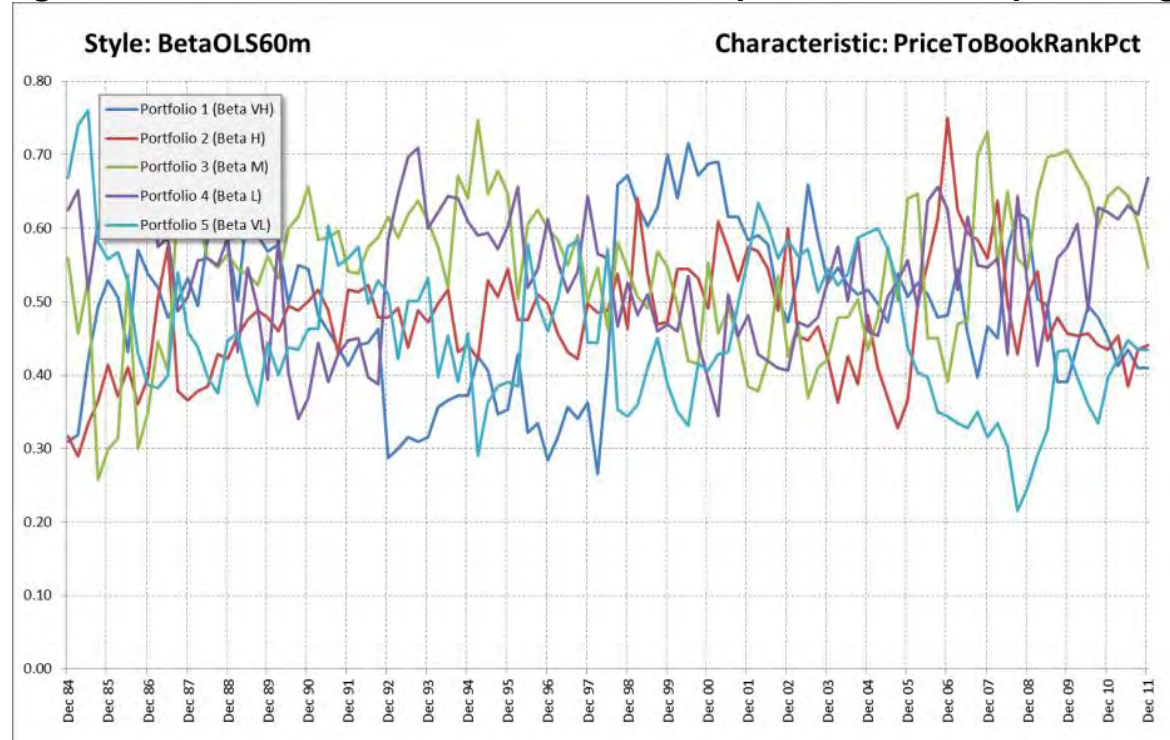

Figure 12: Portfolio characteristic: Price to book rank percentage

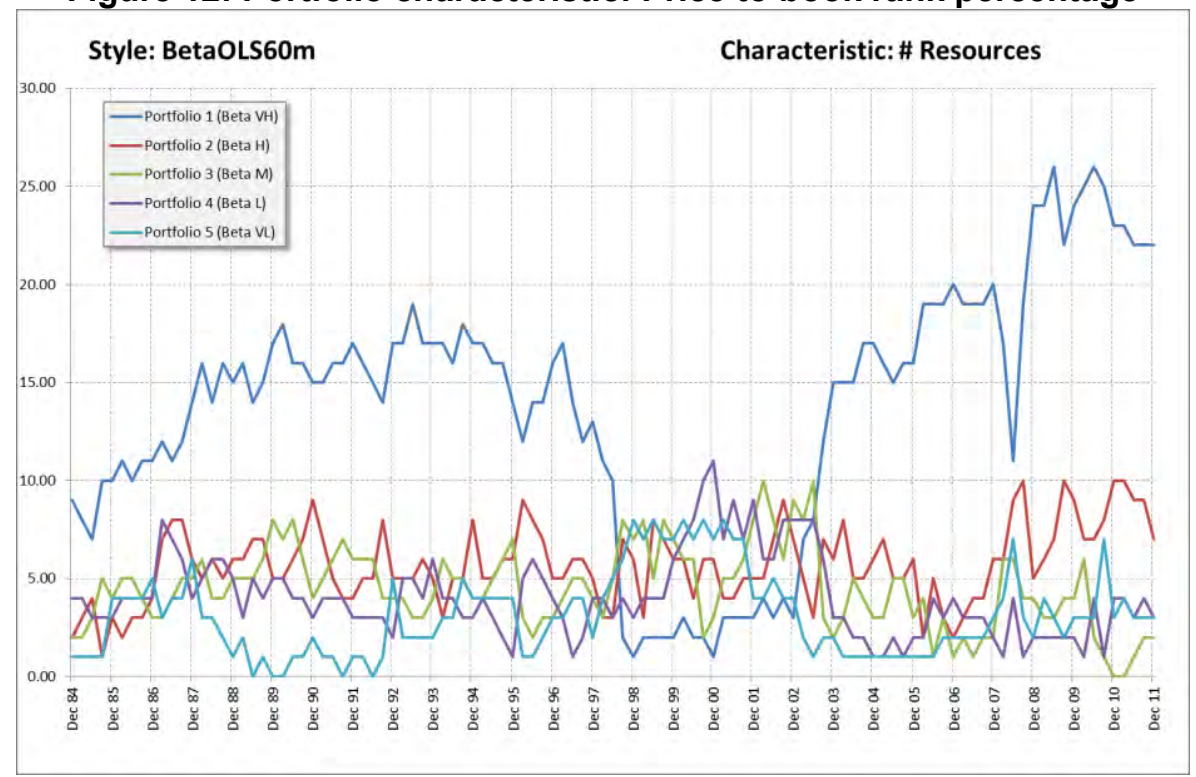

Figure 13: Portfolio characteristic: Number of resource shares 
Across all quintiles and over the full time series, we observe a positive association between beta, size (market capitalisation) and resource shares. We also observe an inverse relationship between these three variables and earnings yield.

\section{CONCLUSIONS}

Using the largest 160 shares on the JSE (99\% of market capitalisation) over 26 years (1985 - 2011), we estimate betas using four different methodologies and form five equal weighted quintile portfolios by ranked beta, with a quarterly review period. We find little difference between the resulting portfolio cumulative returns for the alternative methods for calculating beta, and conclude that (for at least the top 160 shares) an OLS estimate of beta using 60 months of out-ofsample data is suitable. In contradiction to the CAPM, we find a monotonic, inverse relationship between beta and returns. Our results support the findings of Fama and French (1992, 2004), Montier (2007), van Rensburg and Robertson (2003) and Strugnell, Gilbert and Kruger (2011). We also observe that although this relationship was evident for the first 15 years of our analysis, the inverse effect appears to have 'washed out' and is not evident after 2004, indicating no association between beta and returns in the last seven years.

We also examine the characteristics of our betaranked quintiles over the time-series. We find positive correlations between beta and size (market capitalisation), and resource shares; a negative association between beta and earnings yield; and no relationship between beta and the price to book ratio. These findings have profound implications for the theory and use of the single parameter Capital Asset Pricing Model, effectively rendering it redundant. We concur with Fama and French (1992): "If assets are priced rationally, our results suggest that stock risks are multi-dimensional" (p 428).

\section{REFERENCES}

Ang A, Hodrick B, Xing $Y$ and Zhang $X$. 2006. The cross-section of volatility and expected returns. Journal of Finance, 61(1):259-299.

Cathcart M. 1997. On persistence in mutual fund performance. Journal of Finance, 52(1):57-82.

Clarke R, de Silva H, and Thorley S. 2006. Minimumvariance portfolios in the U.S. equity market. The Journal of Portfolio Management, 33(1):10-24.

Davies G and de Servigny A. 2011. Behavioral investment management: An efficient alternative to modern portfolio theory. McGraw-Hill.
Dimson, E. 1979. Risk measurement when shares are subject to infrequent trading. Journal of Financial Economics, 5:263-278.

Fama E. 1970. Efficient capital markets: A review of theory and empirical work. Journal of Finance, 25(2): 383-417. doi:10.2307/2325486. JSTOR 2325486.

Fama E and French K. 1992. The cross-section of expected stock returns. Journal of Finance, 47:427466.

Fama E and French K. 2004. The capital asset pricing model: Theory and evidence. Journal of Economic Perspective, 18:25-46.

Gordon MJ. 1959. Dividends, earnings and stock prices. Review of Economics and Statistics, 41(2):99105. doi:10.2307/1927792. JSTOR 1927792.

Hillier D, Ross S, Westerfield R, Jaffe J and Jordan B. 2010. Corporate finance, European Edition. McGrawHill Education, Berkshire.

Lintner J. 1965. The valuation of risk assets and the selection of risky investments in stock portfolios and capital budgets. Review of Economics and Statistics, 47(1):13-37.

Markowitz HM. 1952. Portfolio selection. The Journal of Finance, 7(1):77-91.

doi:10.2307/2975974. JSTOR 2975974.

Mossin J. 1966. Equilibrium in a capital asset market. Econometrica, 34(4):768-783.

Montier J. 2007. Behavioural investing: A practitioner's guide to applying behavioural finance. John Wiley and Sons, New York.

Scholes M and Williams J. 1977. Estimating betas from nonsynchronous data. Journal of Financial Economics, 5(3):309-327. doi:10.1016/0304-405X(77)90041-1.

Sharpe W. 1964, Capital asset prices: A theory of market equilibrium under conditions of risk. Journal of Finance, 19(3):425-442.

Strugnell D, Gilbert E and Kruger R. 2011. Beta, size and value effects on the JSE. Investment Analysts Journal, 74:1-17.

Treynor J. 1961. Market value, time, and risk. Unpublished manuscript dated 8/8/61, No. 95-209.

Van Rensburg P and Slaney K. 1997. Market segmentation on the Johannesburg Stock Exchange. Journal for Studies in Economics and Econometrics, 23(3):1-23. 
Van Rensburg P. 2001. A decomposition of style based risk on the JSE. Investment Analysts Journal, 54:45-60.

Van Rensburg P and Robertson M. 2003. Size, PE, beta and JSE returns. Investment Analysts Journal, 58:1-11.

Wikipedia 2012.

http://en.wikipedia.org/wiki/Capital_asset_pricing_mod

el accessed 12 January 2012. 